\title{
Immediate physical therapy in dogs with rupture of the cranial cruciate ligament submitted to extracapsular surgical stabilization
}

\author{
[Fisioterapia imediata em cães com ruptura do ligamento cruzado cranial submetidos \\ à estabilização extracapsular] \\ L. Berté ${ }^{1}$, A. Mazzanti ${ }^{2 *}$, F.Z. Salbego ${ }^{1}$, D.V. Beckmann ${ }^{1}$, R.P. Santos ${ }^{1}$, \\ D. Polidoro ${ }^{3}$, R. Baumhardt ${ }^{3}$ \\ ${ }^{1}$ Aluna de pós-graduação - Universidade Federal de Santa Maria - UFSM - Santa Maria, RS \\ ${ }^{2}$ Universidade Federal de Santa Maria - UFSM - Santa Maria, RS \\ ${ }^{3}$ Alunos de graduação - Universidade Federal de Santa Maria - UFSM - Santa Maria, RS
}

\begin{abstract}
The study evaluated the influence of immediate physical therapy on the functional recovery of hind limbs of dogs with experimental cranial cruciate ligament rupture which underwent surgical extracapsular stabilization as well as to verify its interference in joint stability. Eight dogs were randomly divided into two groups: GI (control) $(n=4)$ and GII (physical therapy) $(n=4)$. The dogs in GII underwent the following therapeutic treatments in the postoperative period: cryotherapy, passive joint movement, massage, passive straightening, neuromuscular electrical stimulation, hydrotherapy (bath and aquatic mat) and therapeutic exercises. We performed evaluations of the thigh circumference, goniometry, X-ray, and knee stability (drawer test). Results did not demonstrate a significant difference between the groups nor between different post-operative times. Regarding gait analysis, we found that the 4 dogs in GI remained in degree 3 of lameness 45 and 90 days postoperatively. However, in GII, one dog remained in degree 345 and 90 days after surgery; one dog changed from degree 3 to 490 days after surgery and the other 2 dogs changed from degree 3 to 590 days after surgery. It is possible to conclude that dogs with CCL rupture that undergo immediate physical therapy demonstrate better results in regards to functional gait recovery. The therapeutic modalities used in the immediate postoperative period did not cause instability of the operated knee. Further studies are needed with a larger number of dogs to indicate the immediate physical therapy in dogs with CCL ligament rupture which underwent extracapsular stabilization.
\end{abstract}

Keywords: dog, knee, surgery, physiotherapy, trauma

\section{RESUMO}

Avaliou-se a influência da fisioterapia imediata na recuperação funcional do membro pélvico de cães com ruptura experimental do ligamento cruzado cranial (LCC) submetidos à estabilização cirúrgica extracapsular $e$ verificou-se sua interferência na estabilidade articular. Foram utilizados oito cães distribuídos, aleatoriamente, em GI ou controle (n=4) e GII ou fisioterapia (n=4). Nos cães do GII, as modalidades terapêuticas empregadas no pós-operatório foram crioterapia, movimentação passiva da articulação, massagem, alongamento passivo, estimulação elétrica neuromuscular, hidroterapia (ducha e esteira aquática) e exercícios terapêuticos. Foram realizadas avaliações da circunferência da coxa, goniometria, radiografias e estabilidade do joelho (teste de gaveta) e os resultados não demonstraram diferença significativa entre os grupos e nos diferentes tempos de pós-operatório. Na análise da marcha, aos 45 dias, todos os cães do GI e do GII apresentaram grau 3 de claudicação. Aos 90 dias, quatros cães do GI permaneceram em grau 3 e no GII, um cão em grau 3, um em grau 4 e dois em grau 5. Conclui-se que cães com ruptura de LCC submetidos à fisioterapia imediata demonstraram melhores resultados quanto à recuperação funcional da marcha e as modalidades terapêuticas empregadas no pós-operatório imediato não ocasionaram instabilidade do joelho operado. Novas pesquisas são necessárias com um maior número de cães para poder indicar a fisioterapia

Recebido em 23 de outubro de 2010

Aceito em 7 de outubro de 2011

*Autor para correspondência (corresponding author)

E-mail: alexamazza@yahoo.com.br 
imediata em cães com ruptura do ligamento cruzado cranial submetidos à estabilização cirúrgica extracapsular.

Palavras-chave: cão, joelho, cirurgia, fisioterapia, trauma

\section{INTRODUCTION}

The cranial cruciate ligament (CCL) is a structure that can be frequently injured (Bollen, 1998) and is one of the main causes of hind limb lameness in dogs (Piermattei et al., 2006; Korvick et al., 1994). The joint becomes unstable after CCL rupture and may be associated with meniscus and osteoarthritis injuries (Piermattei et al., 2006). The aetiologies of CCL rupture can be traumatic (Vasseur, 1993) due to degenerative alterations (Piermattei et al., 2006), arthritis, and immune-mediated synovitis or due to changes caused by disuse and age (Johnson and Johnson, 1993). The recommended treatment is surgery, which should be completed immediately after diagnosis of CCL rupture. Surgical reconstitution can use either intra- or extracapsular technique (Piermattei et al., 2006) and aims to restore joint anatomy and stability, preventing the development of degenerative joint injury (Boschin et al., 2002).

Patients can present difficulties in supporting the injured appendage after surgical joint stabilization, causing undesirable consequences such as muscular atrophy, decreased range of joint motion and increased recovery time (Manning et al., 1997). In these cases, physical therapy is recommended to assist in rapid functional recovery, decreasing the possibilities of disuse sequela and improving the patient's quality of life (Levine et al., 2005). Despite the benefits of physical therapy in patients that undergo orthopaedic surgery, some surgeons are still reluctant to recommend it, believing that it might cause clinical worsening of the limb (Davidson et al. 2005). However, few studies have demonstrated such detrimental alterations.

Thus, this experiment aimed to evaluate the influence of physical therapy on the functional recovery of hind limbs of dogs with experimental CCL rupture submitted to surgical extracapsular stabilization and to verify its interference in joint stability.

\section{MATERIALS AND METHODS}

We used eight adult dogs, both male and female, and of no particular breed, weighing between 10.6 and $19 \mathrm{~kg}$. Animals were obtained from our institution's Central Animal Facility. Clinical, laboratory and radiographic evaluations of the hind limbs were completed. The research project was sent to the Ethics in Research Committee in the Institution and was approved and found to be in agreement with administrative process number 23081.003283/2010-50. After the experiment, all animals were donated to the community.

All eight dogs were submitted to extracapsular knee stabilization and randomly distributed into two groups called GI $(n=4)$, or control, and GII $(n=4)$, or physical therapy. Lateral arthrotomy of the right knee was completed in the dogs from GI and GII for CCL sections and removal, followed by capsulorrhaphy with suture using monofilament nylon 2-0. For the extracapsular knee stabilization, we used the modified retinacular imbrication technique (Flo et al., 1975) using monofilament nylon 1 thread. During the postoperative period dogs received analgesic drugs (morphine sulphate at a dose of $1.0 \mathrm{mg} / \mathrm{kg}$, QID, in the first $24 \mathrm{~h}$ ) and a nonsteroidal anti-inflammatory drug (fluxinin meglumine at a dose of $0.5 \mathrm{mg} / \mathrm{kg}$ SID for 3 days).

Immediately after completing the surgical procedure, the right knee joint of the dogs in GII was wrapped in a bag of ice for $25 \mathrm{~min}, 4$ times per day, with a $4 \mathrm{~h}$ interval between each application for a total of $72 \mathrm{~h}$. Upon completing each cryotherapy session, we started passive joint movement (PJM) on the right knee, with limited amplitude by goniometer between $60^{\circ}$ and $120^{\circ}$, totaling 15 cycles (extension/flexion), repeated 3 times.

Seventy-two hours after surgery, it was started the physical therapy protocol, which was performed 3 times per week for 6 weeks (18 sessions). The muscles of the thigh, leg, and right knee underwent a low-pressure bath (30pps) at $37^{\circ} \mathrm{C}$ for $15 \mathrm{~min}$ for 4 weeks. Next, the dog was restrained in the left lateral decubitus position 
and received massage of the thigh and leg muscles through the superficial gliding method in the distal-proximal direction for $10 \mathrm{~min}$ for 4 weeks. The right knee PJM was completed while maintaining angulations between $60^{\circ}$ and $120^{\circ}$ with the aid of a goniometer, totaling 15 cycles with three repetitions. The right knee passive straightening was done in flexion and extension for $30 \mathrm{sec}$ in each position and repeated 15 times. For the neuromuscular electrical stimulation (NMES), the dog remained in the left lateral decubitus position, and with the right thigh already undergoing trichotomy, a 2-mm layer of conducting gel was applied to the four electrodes, two of which were fixed to the respective motor points of the semitendinosus and vastus lateralis muscles and the others as distal as possible, closing the quadripolar current. The emitted current was an average frequency (RUSSIAN) homogeneously alternating $2500 \mathrm{~Hz}$ sine wave, modulated at low frequency $(50 \mathrm{~Hz})$. The current used had sufficient intensity to contract the muscle without causing discomfort, with a rising pulse slope (rise) of $3 \mathrm{sec}$, descending pulse slope (decay) of $3 \mathrm{sec}$, and an on:off ratio of 1:3, meaning $12 \mathrm{sec}$ of stimulation for $36 \mathrm{sec}$ of rest. We used a reciprocal method and the procedure was carried out for $30 \mathrm{~min}$ for 5 weeks.

During the second week, we added to the protocol the modalities of aquatic mat, walking on soft ground and ball exercises. The dogs were placed on an aquatic mat on two water levels, the first at the greater trochanter region and the second at the level of the malleolus of the tibia. The dogs remained on the aquatic mat for a period of 5 to $10 \mathrm{~min}$ in each water level. They were then walked on soft ground (lawn) with a leash for 10min. For the ball exercises, the dogs were placed on a therapeutic ball $65 \mathrm{~cm}$ in diameter in a standing position, with the ball going backwards and forwards a total of 20 times.

Starting on the third week, the dogs began walking on hard ground, still wearing a leash, for $10 \mathrm{~min}$. At the same period, the dogs started five repetitions of walking on a ramp at a $20^{\circ}$ angle. During the fourth week, therapeutic exercises using cones, obstacles, platforms, and a foam mattress were added to the protocol. For the cone exercises, the dogs walked through cones arranged in a figure-eight shape, at a distance established by the length of the dog, totaling a distance of approximately $10 \mathrm{~m}$. Dogs repeated this course 5 times. The obstacles were mounted with two $2.5 \mathrm{~m}$ wooden boards with holes separated by $50 \mathrm{~cm}$ and with wooden bars inserted at a height of $12 \mathrm{~cm}$ from the ground. The dogs walked through the obstacles, repeating the track five times. The platform exercise was completed with an $80 \mathrm{~cm}$ diameter circular board with a $10 \mathrm{~cm}$ wooden chock fixed below the platform. The dogs were placed on the stationary platform and the 20 circular movements promoted weight changes on the supported appendages. Walks on the $10 \mathrm{~cm}$ thick foam mattress, totaling a track of approximately $10 \mathrm{~m}$, were completed 10 times.

In the fifth week, we applied the NMES, aquatic mat, walking (lawn and hard ground), ball, ramp, cones, obstacles, platform, and foam mattress protocols. In the sixth week, we used the aquatic mat, walking (lawn and hard ground), ball, ramp, cones, obstacles, platform, and foam mattress protocol modalities.

The evaluations performed measured gait, thigh circumference, knee joint goniometry, and hind limb X-rays. All measurements were taken 45 and 90 days after surgery. The drawer test was also evaluated in the immediate postoperative period, before the application of the first cryotherapy session. For gait analysis, the dogs were kept on a leash and evaluated while walking and running. Gait analysis was done by a single evaluator, clinically estimating the degree of lameness in accordance to the parameters of Tudury and Raiser (1985). These parameters are classified as degree 1 , where the dogs do not use or support the appendage; degree 2 , which indicates infrequent use and support of the appendage during walking and running but no support of body weight on the appendage when standing; degree 3 , which shows partial support of body weight on the affected appendage and use of the appendage when walking and a limp while running; degree 4, which indicates walking without a limp and normal standing position, a limp while running without raising the appendage; and degree 5, which shows the functional use of the appendage.

With the dog positioned in lateral decubitus, we performed circumference measurement of the 
right thigh in three places (proximal, half and distal) using a flexible measuring tape graduated in centimeters. While the dog was still in the lateral decubitus position, goniometry was completed with the center of the complete circle goniometer at the knee joint and positioning one of the rulers in the greater trochanter and the other in the tibial axial while conducting extension and flexion movements. The measurements of the thigh circumference and goniometry were repeated three times and the average was recorded.

For the radiographic evaluation of knee joints (craniocaudal and mediolateral incidence), the dogs were anaesthetized with propofol (10.0mg/kg IV). After X-ray radiography and with the dogs still anaesthetized, the knee drawer test was done to evaluate the joint stability degree according to criteria of Chauvet et al. (1996), which classify degree 1 as accented movements (above $5 \mathrm{~mm}$ ), degree 2 as moderate movement $(3-5 \mathrm{~mm})$, degree 3 as discrete movements (1-2mm) and degree 4 as absence of movement. All X-rays were digitized and evaluated by two examiners ( 1 and 2 ) in a blind study. The evaluations consisted of defining the $\mathrm{X}$-ray image according to the classification of Muzzi et al. (2009) as follows: 1 for femorotibiopatelar joint without alteration, 2 for discrete joint effusion alterations, discrete periarticular osteophyte formation at the patellar extremities, and caudal surface of the tibial condyles, 3 for moderate alterations, moderate joint effusion alterations, moderate periarticular ostephytes in the trochlear ridges of the femur, fabelo, fibula head, medial surfaces and/or lateral femoral condyles and 4 for accented alterations with formation of intra-joint ostephytes (the joint surface of the tibial plateau and intercondylar notch) and subchondral bone sclerosis.

The Friedman and Kruskal-Wallis nonparametric tests were used for statistical analysis. The first test evaluated the individual at different periods and the second evaluated the different groups. The Wilcoxon test was used only for the evaluation of the joint goniometry, which evaluates two related samples.

\section{RESULTS AND DISCUSSION}

The physical therapy protocol used in this research was defined according to the healing phase without intervening in the functioning of the implant, as suggested by Piermatei et al. (2006). Marsolais et al. (2002), Davidson et al. (2005) and Monk et al. (2006), who noted that the rehabilitation in dogs undergoing extracapsular stabilization with the intention of improving joint amplitude and weight support must begin on the first postoperative day to reduce muscle spasms and prevent muscular atrophy. Schenck et al. (1997) completed a study with the rupture of the anterior crucial ligament in humans who underwent rehabilitation and observed improvement in their quality of life. It is important to highlight that the current concern in veterinary medicine is animal well-being, which can be improved by physical therapy, since it is an important and indispensable adjuvant therapy in the postoperative recovery of orthopaedic patients.

Regarding gait analysis, it was found that the 4 dogs in GI remained in degree 3 of lameness 45 and 90 days postoperatively. However, in GII, one dog remained in degree 3, 45 and 90 days after surgery; one dog changed from degree 3 to 4, 90 days after surgery and the other 2 dogs changed from degree 3 to 5, 90 days after surgery (Figure 1A and 1B). Thus, although there was no significant difference between groups, we verified that only dogs in GII $(n=2)$ presented functional gait recovery at 90 days compared to those in GI that remained $(n=4)$ in degree 3 , probably influenced by the physical therapy modalities used in this study. This was also demonstrated by Marsolais et al. (2002) and Monk et al. (2006), who studied the effects of immediate postoperative rehabilitation of dogs that underwent surgical stabilization of CCL rupture and also found that physical therapy prevented sequela caused by joint disuse of the operated appendage. Baraúna Júnior et al. (2007), in an experiment on CCL stabilization in dogs using extracapsular femorofabelotibial interconnection technique, completed immediate postoperative cryotherapy for $48 \mathrm{~h}$ and PJM for 4 weeks and observed functional improvement in the dogs after 180 days. On the other hand, Muzzi et al. (2009) observed gradual improvement in the degree of lameness after only 30 days in an intracapsular technique study substituting CCL for autogenous fascia lata graft in dogs associated with a physical therapy program. 
In the analysis of thigh circumference preoperatively, GI showed on average $32.55 \mathrm{~cm}$, $27.44 \mathrm{~cm}$ and $23.1 \mathrm{~cm}$ for the proximal, middle and distal thigh, respectively; on day 45 postoperatively, we observed $29.77 \mathrm{~cm}$ (proximal), $26.16 \mathrm{~cm}$ (middle) and $22.27 \mathrm{~cm}$ (distal); and on day 90 we found $31.66 \mathrm{~cm}$ (proximal), $27.66 \mathrm{~cm}$ (middle) and $23.16 \mathrm{~cm}$ (distal). However, dogs in GII had preoperative values of $29.70 \mathrm{~cm}$ (proximal), $25.37 \mathrm{~cm}$ (middle) and $21.83 \mathrm{~cm}$ (distal); on day 45 we found $30.03 \mathrm{~cm}$ (proximal), $25.37 \mathrm{~cm}$ (middle) and $20.79 \mathrm{~cm}$ (distal); and on day $90,30.58 \mathrm{~cm}$ (proximal) $25.74 \mathrm{~cm}$ (middle) and $21.49 \mathrm{~cm}$ (distal). There was no significant difference between the groups (Figure 2A and 2B). The circumference averages of the dogs in GII remained constant with minimum variation in the three regions during the pre-established postoperative periods. This probably occurred due to the NMES, which assisted in the prevention of the atrophy by disuse, as described by Levine et al. (2005) and Pelizzari et al. (2008). Johnson et al. (1997) observed that dogs treated with NMES after surgery for CCL rupture improved leg use on the ground, increased thigh circumference and reduced the presence of radiographic alterations. This indicates that the use of NMES during the postoperative period is useful in avoiding muscular atrophy by disuse, mainly while the patient cannot support the appendage on the ground.

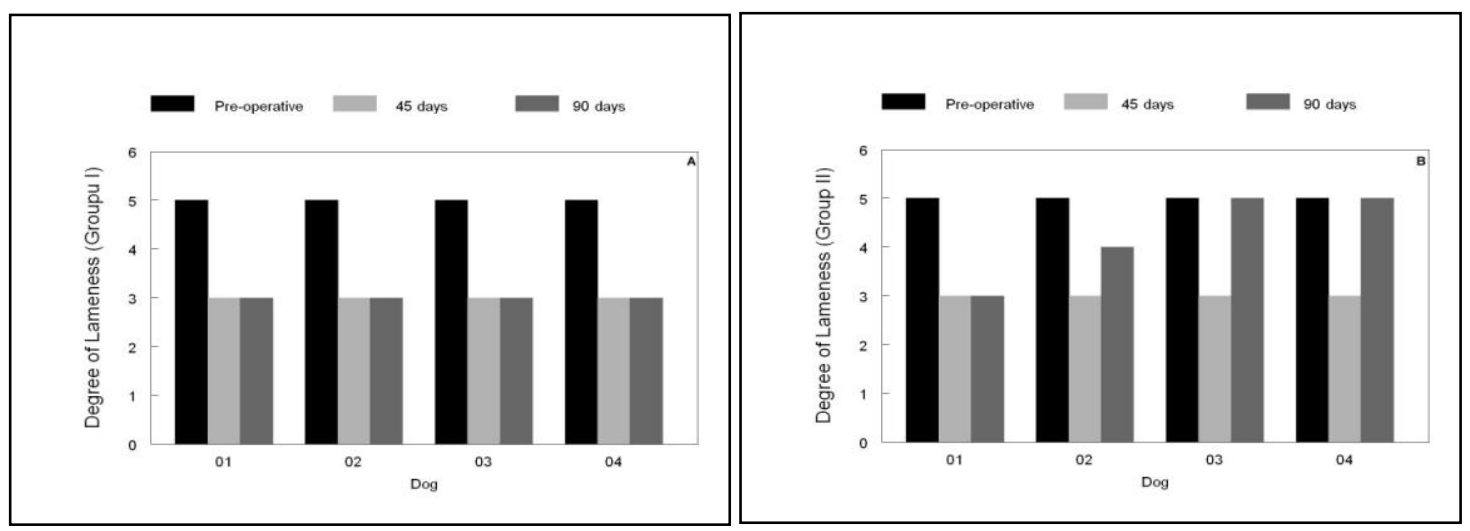

Figure 1. Degree of lameness in dogs with rupture of the cranial cruciate ligament submitted to extracapsular surgical stabilization. Note that all dogs in GI (A) remained in degree 3 of lameness at 90 days, while two dogs in GII (B) had a functional use of the member in the same period.
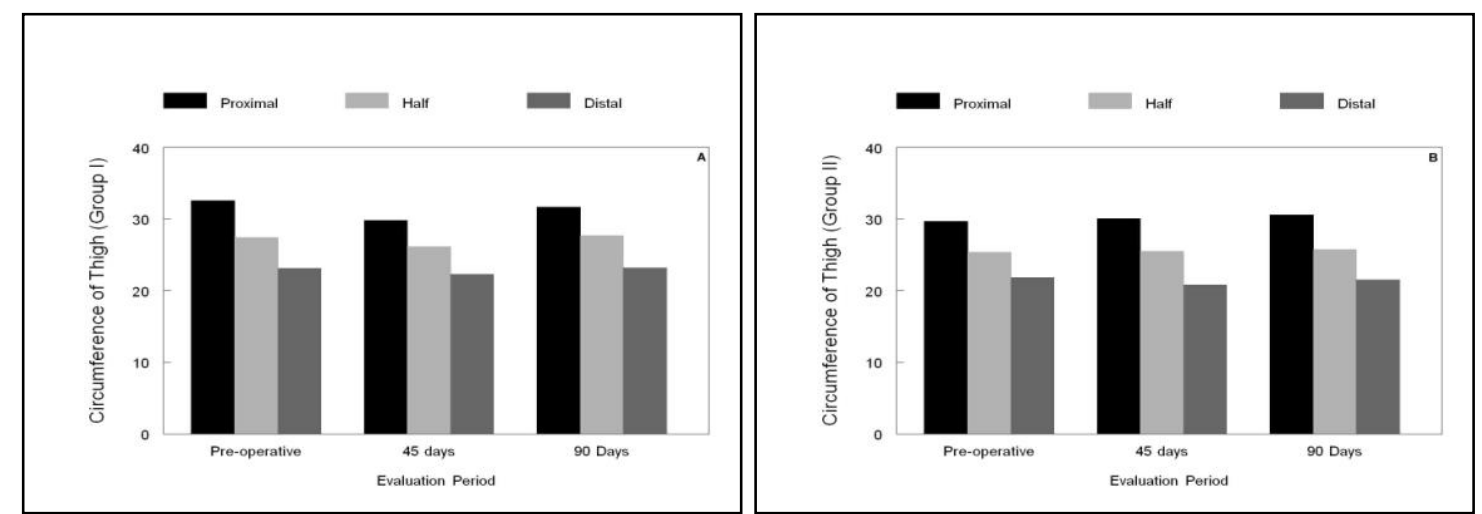

Figure 2. Thigh circumference mean in three places (proximal, half and distal) in dogs with rupture of the cranial cruciate ligament submitted to extracapsular surgical stabilization without (A) (GI) or with (B) (GII) immediate physical therapy. In the GII the circumference of thigh remained constant, with minimum variation in the three regions during the pre-established postoperative periods. 
The knee goniometry presented the following extension and flexion averages for dogs in GI in the preoperative period: $18.44^{\circ}$ and $157.77^{\circ}$, $25.99^{\circ}$ and $165.99^{\circ}$ at 45 days and $23.77^{\circ}$ and $160.88^{\circ}$ at 90 days. With GII, the averages were $17.16^{\circ}$ and $159.16^{\circ}$ in the preoperative period, $19.49^{\circ}$ and $161.99^{\circ}$ at 45 days, and $14.49^{\circ}$ and $162.99^{\circ}$ at 90 days after the surgery, with no statistical differences between groups (Figure 3A and $3 \mathrm{~B}$ ). It was found that dogs in GI had, on average, a worsening of $23.76 \%$ and in GII an improvement of $18.4 \%$ in the amplitude of the flexed knee when compared to the preoperative goniometry and 90 days elapsed from surgery; whereas for length, an improvement in the joint range of $1.97 \%$ and $2.41 \%$ for GI and GII was observed, respectively. Although not verifying a significant difference between the groups, we can affirm that the beginning of immediate passive motion of the knee joint of dogs in GII probably influenced this result because according to Manning et al. (1997) the passive motion of the articulation is indicated to increase and maintain range of motion. Monk et al. (2006) observed that PJM and NMES used in the immediate post-operative period provided greater joint amplitude of the operated appendage compared to the contralateral limb for reducing the formation of joint contractures and adhesions.
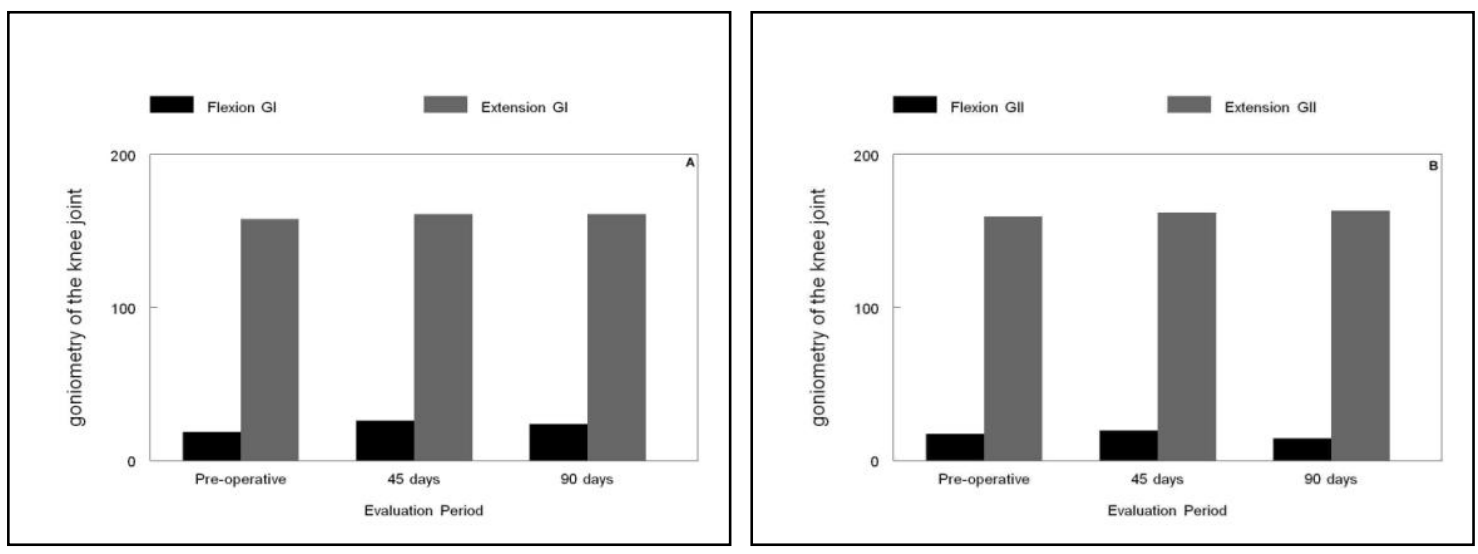

Figure 3. Goniometry of the knee joint mean for dogs with rupture of the cranial cruciate ligament submitted to extracapsular surgical stabilisation without (A) (GI) or with (B) (GII) immediate physical therapy.

As for the radiographic analysis, examiner 1 assigned score 1 in a craniocaudal and mediolateral impact in the preoperative period, 45 and 90 days. However, examiner 2 found two dogs in GI with subtle changes (score 2), one dog at 45 and the other at 90 days, both with the lateral incidence. Two dogs from GII were assigned score 2, one dog with the craniocaudal incidence at 45 and 90 days and one dog in the lateral incidence at 90 days. In this research, even performing the surgeries immediately after the rupture of the cranial cruciate ligament, discrete X-ray changes (score 2) of the knee joint at 45 days were observed by one of the examiners. On the other hand, Kirby (1993) did not verify degenerative joint disease in dogs with CCL ruptures who underwent immediate surgical reconstitution. Muzzi et al. (2009) observed joint alterations starting at 30 days, with injury aggravation at 90 days, and noted that the use of physical therapy did not influence in the formation of periarticular osteophytes. Baraúna Júnior et al. (2007) found that $84.6 \%$ of knees stabilized with the extracapsular femoro-fabelotibial interconnection technique showed radiographic evidence of degenerative alterations 180 days after surgery.

Concerning knee stability, as evaluated by the drawer test, the results demonstrated that even with a discrete instability in the immediate postoperative period (degree 3 ), the use of physical therapy in dogs from GII with passive physical therapeutic modalities did not cause aggravation, as demonstrated in Figure 4A and 4B. Therefore, the use of passive exercise soon after the surgery is recommended, without concern that knee stabilization failure will occur in dogs with CCL rupture undergoing extracapsular surgical stabilization. Johnson e 
Levine (2004) commented that cranial drawer movement can remain for weeks after surgical reconstitution and that rehabilitation can reduce this instability. On the other hand, Smith (2000) mentioned that the permanence of the drawer test verified immediately after surgery can be

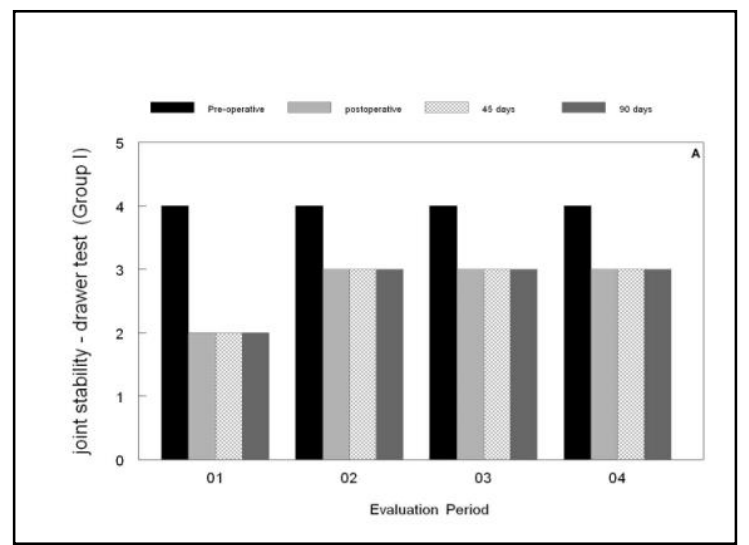

attributed to the use of monofilament nylon sutures, which can loosen due to their elasticity and plastic deformation, squeezing and deforming the knot. Additionally, the positioning of the suture wire fixation in the lateral and medial fabelo can contribute to joint stability.

Figure 4. Knee stability evaluated through the drawer test in dogs with rupture of the cranial cruciate ligament submitted to extracapsular surgical stabilization without (A) (GI) or with (B) (GII) immediate physical therapy. Note that dogs in G II (B) presented no change in the degree of joint stability, demonstrating that the immediate physical therapy did not affect this result.

\section{CONCLUSIONS}

It is possible to conclude that dogs with $\mathrm{CCL}$ rupture that undergo physical therapy immediately after surgical extracapsular stabilization demonstrated better results regarding functional gait recovery. Furthermore, therapeutic modalities used in the immediate postoperative period did not cause instability of the operated knee. Further studies are needed with a larger number of dogs to indicate the immediate physical therapy in dogs with CCL ligament rupture that underwent extracapsular stabilization.

\section{REFERENCES}

BOLLEN, S. Ligament injuries of knee: limping forward. Br. J. Sports Med., v.32, p.82-84, 1998.

BOSCHIN, L.C.; SCHUCK, G.F.; OLIVEIRA, G.K. et al. Artrotomia "versus" artroscopia: avaliação pósoperatória da reconstrução do ligamento cruzado anterior. Rev. Bras. Ortop., v.37, p.30, 2002.

BARAÚNA JÚNIOR, D.; ROEHSIG, C.; ROCHA, L.B. et al. Técnica de interligação extracapsular fêmoro-fabelo-tibial na ruptura do ligamento cruzado cranial em cães: achados clínicos e radiográficos. Cienc. Rural, v.37, p.769-776, 2007.
CHAUVET, A.E.; JOHNSON, A.L.; PIJANOWSKI, G.J. et al. Evaluation of fibular head transposition, lateral fabellar suture, and conservative treatment of cranial cruciate ligament rupture in large dogs: retrospective study. J. Am. Anim. Hosp. Assoc.,v.32, p.247-255, 1996.

DAVIDSON, J.R.; KERWIN, S.C.; MILLIS, D.L. Rehabilitation for the orthopedic patient. Vet. Clin. N. Am.: Small Anim. Pract.,v.35, p.1357-1388, 2005.

FLO, G. Modification of the lateral retinacular 306 imbrication technique for stabilizing cruciate ligament injuries. J. Am. Anim. Hosp. Assoc. v.11, p.570-576, 1975.

JOHNSON, J.M.; JOHNSON, A.L.; PIJANOWSKI, G.J. et al. Rehabilitation of dogs with surgically treated cranial cruciate ligament-deficient stifles by use of electrical stimulation of muscles. Am. J. Vet. Res., v.58, p.1473-1478, 1997.

JOHNSON, J.M.; JOHNSON, A.L. Cranial cruciate ligament rupture. pathogenesis, diagnosis and postoperative rehabilitation. Vet. Clin. N. Am.: Small Anim. Pract., v.23, p.717-733, 1993.

JOHNSON, J.; LEVINE, D. Electrical stimulation. In: MILLIS, D.L.; LEVINE, D.; TAYLOR, R.A. (Eds). Canine rehabilitation physical therapy. Philadelphia: Saunders. 2004. p.289-302.

KIRBY, B.M. Decision-making in cranial cruciate ligament ruptures. Vet. Clin. N. Am.: Small Anim. Pract., v.23, p.797-819, 1993. 
KORVICK, D.L.; JOHNSON, A.L.; SCHAEFFER, D.J. Surgeon's preference in treating cranial cruciate ligament ruptures in dogs. J. Am.: Vet. Med. Assoc., v.205, p.1318-1324, 1994.

LEVINE, D.; MILLIS, D.J.; MARCELLIN-LITTLE, D.J. Introduction to veterinary physical rehabilitation. Vet. Clin. N. Am. Small Anim. Pract., v.35, p.1247$1254,2005$.

MANNING, A.M.; RUSH, J.; ELLIS, D.R. Physical therapy for critically ill veterinary patients. Part II. The musculoskeletal system. Comp. Contin. Educ. Pract. Vet., v.19, p.803-807, 1997.

MARSOLAIS, G.S.; DVORAK, G.; CONZEMIUS M.G. Effects of postoperative rehabilitation on limb function after cranial cruciate ligament repair in dogs. J. Am. Vet. Med. Assoc., v.220, p.1325-1330, 2002.

MONK, M.L.; PRESTON, C.A.; McGOWAN, C.M Effects of early intensive postoperative physiotherapy on limb function after tibial plateau leveling osteotomy in dogs with deficiency of the cranial cruciate ligament. Am. J. Vet. Res., v.67, p.529-536, 2006.

MUZZI, L.A.L.; REZENDE, C.M.F.; MUZZI, R.A.L. Fisioterapia após substituição artroscópica do ligamento cruzado cranial em cães. I - avaliação clínica, radiográfica e ultrassonográfica. Arq. Bras. Med. Vet. Zootec., v.61, p.805-814, 2009.
PELIZZARI, C.; MAZZANTI, A.; RAISER, A.G. et $a l$. Estimulação elétrica neuromuscular de média frequência em cães com atrofia muscular induzida. Cienc. Rural, v.38, p.736-742, 2008.

PIERMATTEI, D.L.; FLO, G.; DECAMP, C.E. The stifle joint. In: (Eds). Brinker, Piermattei and Flo's handbook of small animal orthopedics and fracture repair. 4.ed. St Louis: Elsevier, 2006. p.562660.

SCHENCK, R.C.; BLASCHAK, M.J.; LANCE, E.D. et al. A prospective outcome study of rehabilitation programs and anterior cruciate ligament reconstruction. Arthroscopy, v.13, p.285-290, 1997.

SMITH, B. Viewpoints in surgery cruciate ligament rupture extracapsular stabilisation. Aust. Vet. J., v.78, p.382-383, 2000.

TUDURY, E.A.; RAISER, A.G. Redução de fraturas distais de fêmur de cães, empregando pinos de Steinmann em substituição aos de Rush. Rev. Centro Cienc. Rurais., v. 15, p.141-155, 1985.

VASSEUR, P.B. Stifle joint. In: SLATTER, D.H. (Ed). Textbook of small animal surgery. Philadelphia: Saunders. 1993. p.1817-1865. 